\title{
Inability to obtain sperm for fresh IVF cycles: analysis and incidence of outcomes using a database from the United States
}

\author{
Alexandra Joice Berger ${ }^{1 *} \mathbb{D}$, Valary Raup ${ }^{1}$, Ramy Abou Ghayda', Andrea Lanes ${ }^{2}$ and Martin Kathrins ${ }^{1}$
}

\begin{abstract}
Background: Azoospermia is present in 10\% of men presenting with infertility and surgical sperm retrieval rates for men with azoospermia due to spermatogenic dysfunction remain low. We investigated the incidence of failed fresh IVF cycles due to inability to obtain sperm and describe predictors for subsequent IVF.

Methods: A national IVF database was used to identify fresh IVF cycles in which there was failure to obtain sperm. Patient linkage was utilized to determine outcomes of subsequent IVF.

Results: 243,291 fresh IVF cycles were identified; 719 (0.3\%) listed "inability to obtain sperm" as reason for embryo non-transfer. Male infertility was a factor in 537 (75\%) and ejaculation was the most common anticipated sperm source (414, 57\%). 713 (99.2\%) cycles resulted in retrieved oocytes, but only 627 (87.2\%) cryopreserved oocytes. 265 (37\%) of couples underwent subsequent IVF. On multivariable analysis, lack of initial oocyte cryopreservation (OR $0.34, p=0.01)$ and male infertility (OR 0.14, $p=0.01)$ were associated with having no subsequent cycles. Partner sperm was used in 213 (80\%) second cycles and sperm retrieval method was largely conserved (181/213, 85\%). Embryos were transferred in 186 (70\%) second cycles. Failed embryo transfers were due to repeat inability to obtain sperm in 5 (6\%) cycles.
\end{abstract}

Conclusions: Failure to obtain sperm during fresh IVF is rare, but most affected couples will not pursue further cycles of IVF after their initial failed attempt.

\section{Introduction}

Azoospermia is present in $3-10 \%$ of men presenting with infertility $[4,16]$. Unfortunately, surgical sperm retrieval (SSR) rates for men with nonobstructive azoospermia (NOA) remain low [8]. Furthermore, other reasons for failure to obtain sperm on the day of in-vitro fertilization (IVF) include ejaculatory dysfunction and transient/unexpected azoospermia. Failure to obtain sperm for assisted reproductive

\footnotetext{
* Correspondence: ajberger@bwh.harvard.edu

Presented as a moderated poster abstract at the American Urological Association Annual Meeting May 2019, Chicago, IL

'Division of Urology, Brigham and Women's Hospital and Harvard Medical School, 45 Francis St ASB-II, Boston, MA 02115, USA

Full list of author information is available at the end of the article
}

therapies is a significant stressor for couples already suffering from infertility.

Multiple different approaches to SSR have been pursued to optimize outcomes. A "fresh" SSR attempt involves timing the man's extraction procedure to a programmed ovulation induction cycle and oocyte retrieval. Failure to obtain sperm in such a scenario is particularly devastating for the couple. An alternative approach involves elective SSR with cryopreservation of sperm-if successful-and use of the thawed specimen later with in-vitro fertilization (IVF) [1]. However, there are technical limitations of sperm cryopreservation in this setting including rare occurrences of complete postthaw cellular loss [6]. Thus, there is no consensus on the optimal approach. 
While individual centers may report outcomes regarding canceled cycles of IVF due to inability to obtain sperm, there is no multi-institutional, national data on the real-world incidence. Furthermore, little is known about the clinical follow-up for such couples regarding their decision to pursue future cycles of IVF. Beyond failed SSR in the setting of azoospermia, there are yet other less common reasons why sperm may not be available-such as failure to obtain sperm from a planned ejaculated specimen-for which no incidence data exists. Herein, we sought to investigate the incidence and clinical outcomes for couples whose fresh IVF cycles were canceled due to an inability to obtain sperm.

\section{Materials and methods}

Exemption was obtained from Institutional Review Board at Brigham and Women's Hospital for this study. A retrospective analysis was performed of the Society for Assisted Reproductive Technology (SART) Clinical Outcome Report System database of all fresh IVF cycles for which there was a failure to obtain sperm. SART is an affiliate society of the American Society of Reproductive Medicine and is a national consortium of assisted reproductive technology centers in the U.S. Relevant data was available from 2014 to 2016 . We analyzed couples' subsequent linked cycles of IVF after their initial failed cycles. Demographic data included region of IVF center, ethnicity of male and female partner, obstetric history, reason for IVF (multiple reasons possible), intended sperm source (ejaculation, epididymal aspirate, testicular extraction, electroejaculation, retrograde ejaculation). Cycles involving a gestational carrier were excluded from our analysis. Outcomes regarding female partner included number of oocytes retrieved and the decision to cryopreserve oocytes.

The statistical analyses were performed utilizing Stata 14 (College Station, TX: StataCorp LP). Chi squared tests and logistic regression analyses were used. A $p$ value of $<0.05$ was regarded as statistically significant and all analyses were two-tailed. Results are presented as odds ratios (OR).

\section{Results}

243,291 total fresh IVF cycles were identified from 2014 to 2016. Amongst these, 719 cycles (including 710 couples) listed "inability to obtain sperm" as the reason for cycle failure, with an annual incidence of $0.3 \%$ (range $0.2-0.4 \%$ ) (Table 1).

The patient demographics for these cycles are included in Table 2. The largest group of patients were White and from the Northeast. Most had no prior pregnancies and had never pursued prior IVF cycles. Male infertility was the reason for IVF in only 537 (75\%) cycles. Ejaculation was the most common anticipated sperm source, followed by testicular biopsy and epididymal aspirate.

Most (99.2\%) cycles resulted in retrieved oocytes, but oocytes were cryopreserved in only $87.2 \%$. On univariate analyses, smoking (vs nonsmoking) as well as reporting years 2015 and 2016 (vs 2014) were associated with cryopreservation. On multivariable analysis, however, only reporting year 2015 and location in the Northeast, Midwest, and West (vs South) were associated with oocyte cryopreservation (Table 3).

265 (37\%) of couples underwent subsequent IVF cycles. On multivariable analysis, lack of cryopreservation of oocytes on initial cycle and an initial diagnosis of male infertility were associated with failure to undergo subsequent cycles (Table 4 and Fig. 1).

Donor sperm was used in 52 (19\%) second IVF cycles. Of the couples who used partner's sperm, the method of sperm retrieval was largely conserved from the first IVF attempt $(181 / 213,85 \%)$. Embryos were transferred in $186(70 \%)$ of second cycles, with a clinical pregnancy rate of $34 \%(89 / 265)$ and a live birth rate of $28 \%(73 /$ 265). Failed embryo transfers during second IVF cycle were due to repeat inability to obtain sperm $(5,6.4 \%)$, oocyte/embryologic reasons $(52,65.8 \%)$ and other reasons $(13,16.5 \%)$.

\section{Discussion}

IVF cycles which are canceled due to an inability to obtain sperm are rare, occurring only in $0.3 \%$ of cycles (1 in 338 cycles). Here, we report the first real-world incidence of such instances based on a national cohort. Most of these couples planned to use ejaculated sperm for IVF, followed by planned use of testicular sperm. We also observed that a minority of couples attempted a subsequent cycle of IVF, with most couples utilizing the same planned sperm source.

Table 1 Yearly incidence of sperm "no retrieval" cycles

\begin{tabular}{llll}
\hline & Number of cycles with failure to obtain sperm & Total number of fresh IVF cycles & Percentage \\
\hline Reporting year & & & $0.2 \%$ \\
2014 & 173 & 85,572 & $0.3 \%$ \\
2015 & 258 & 81,712 & $0.4 \%$ \\
2016 & 288 & 76,007 & $0.3 \%$ \\
Overall & 719 & 243,291 & \\
\hline
\end{tabular}


Table 2 Sperm "no retrieval" cycle demographics. Total patients $=719$

\begin{tabular}{|c|c|c|}
\hline & $\begin{array}{l}\text { Number of cycles with } \\
\text { failure to obtain sperm }\end{array}$ & \\
\hline \multicolumn{3}{|l|}{ Reporting year } \\
\hline 2014 & 173 & $24.1 \%$ \\
\hline 2015 & 258 & $35.9 \%$ \\
\hline 2016 & 288 & $40.1 \%$ \\
\hline \multicolumn{3}{|l|}{ Clinic region } \\
\hline Northeast & 290 & $40.3 \%$ \\
\hline South & 242 & $33.7 \%$ \\
\hline West & 95 & $13.2 \%$ \\
\hline Midwest & 92 & $12.8 \%$ \\
\hline \multicolumn{3}{|c|}{ Race } \\
\hline White & 216 & $30.0 \%$ \\
\hline Black & 70 & $9.7 \%$ \\
\hline Hispanic & 28 & $3.9 \%$ \\
\hline Asian & 55 & $7.6 \%$ \\
\hline Native American & 1 & $0.1 \%$ \\
\hline Unknown & 351 & $48.8 \%$ \\
\hline \multicolumn{3}{|l|}{ Gravidity } \\
\hline 0 & 447 & $62.2 \%$ \\
\hline 1 to 2 & 199 & $27.7 \%$ \\
\hline $3+$ & 71 & $9.9 \%$ \\
\hline Unknown & 2 & $0.3 \%$ \\
\hline \multicolumn{3}{|l|}{ Prior fresh cycles } \\
\hline 0 & 504 & $70.1 \%$ \\
\hline 1 to 2 & 178 & $24.8 \%$ \\
\hline $3+$ & 37 & $5.1 \%$ \\
\hline \multicolumn{3}{|c|}{ Reason for infertility (more than one is possible) } \\
\hline Male infertility & 537 & $74.7 \%$ \\
\hline Endometriosis & 24 & $3.3 \%$ \\
\hline PCOS & 64 & $8.9 \%$ \\
\hline Diminished ovarian reserve & 143 & $19.9 \%$ \\
\hline Tubal issues & 63 & $8.8 \%$ \\
\hline Uterine & 39 & $5.4 \%$ \\
\hline Unexplained & 32 & $4.5 \%$ \\
\hline \multicolumn{3}{|l|}{ Complication } \\
\hline No & 712 & $99.0 \%$ \\
\hline Yes & 7 & $1.0 \%$ \\
\hline Infection & 1 & $0.1 \%$ \\
\hline Hyperstimulation & 4 & $0.6 \%$ \\
\hline Other & 3 & $0.4 \%$ \\
\hline \multicolumn{3}{|l|}{ Sperm source } \\
\hline Ejaculation & 414 & $57.6 \%$ \\
\hline Testicular & 251 & $34.9 \%$ \\
\hline
\end{tabular}

Table 2 Sperm "no retrieval" cycle demographics. Total patients $=719$ (Continued)

\begin{tabular}{lll}
\hline & $\begin{array}{l}\text { Number of cycles with } \\
\text { failure to obtain sperm }\end{array}$ \\
\hline Epidiymal & 50 & $7.0 \%$ \\
Retrograde ejaculation & 1 & $0.1 \%$ \\
Electro-ejaculation & 1 & $0.1 \%$ \\
Unknown & 2 & $0.3 \%$ \\
Oocytes retrieved & & \\
No & 6 & $0.8 \%$ \\
Yes & 713 & $99.2 \%$ \\
Oocytes frozen & & \\
No & 92 & $12.8 \%$ \\
Yes & 627 & $87.2 \%$ \\
\hline
\end{tabular}

Inability to obtain sperm is the most feared outcome for an azoospermic man undergoing planned SSR in conjunction with programmed ovulation induction, or "fresh" testicular sperm extraction (TESE). For men with azoospermia due to spermatogenic dysfunction, also known as non-obstructive azoospermia, sperm retrieval rates (SRR) remain relatively low. A recent meta-analysis showed successful retrieval occurs in only $52 \%$ of surgeries when microsurgical testicular sperm dissection is performed [2]. However, for "fresh" TESE, availability of an operating microscope may be limited as may operating room availability, so a conventional nonmicrosurgical TESE must be carried out. For that latter procedure, successful retrieval rates are lower.

For men with obstructive azoospermia (OA), such as those who have undergone prior vasectomy, SRR should be practically $100 \%$ [3]. Even if initial percutaneous testicular or epididymal aspiration attempts are unsuccessful, a "back-up" approach employing conventional TESE will almost always be successful. Interestingly, we observed that epididymal aspirate was the planned sperm in $7 \%$ of such failed cycles. It is unclear why these couples did not undergo same-day open TESE after aspiration failed to obtain sperm. However, while nomogram predictions, reliant on testicular size and serum $\mathrm{FSH}$, are highly effective at differentiating between men with NOA and idiopathic OA, they are not perfectly accurate [13]. Furthermore, men with underlying diffuse maturation arrest testicular histology may have larger testicles and relatively lower FSH, relative to other men with NOA [17], and may be mistakenly planned for an epididymal aspirate. Thus, scenarios in which a "fresh" TESE is planned with the assumption of a high retrieval rate due to presumed obstructive physiology, may in fact result in failure to obtain sperm due to unexpected spermatogenic dysfunction. 


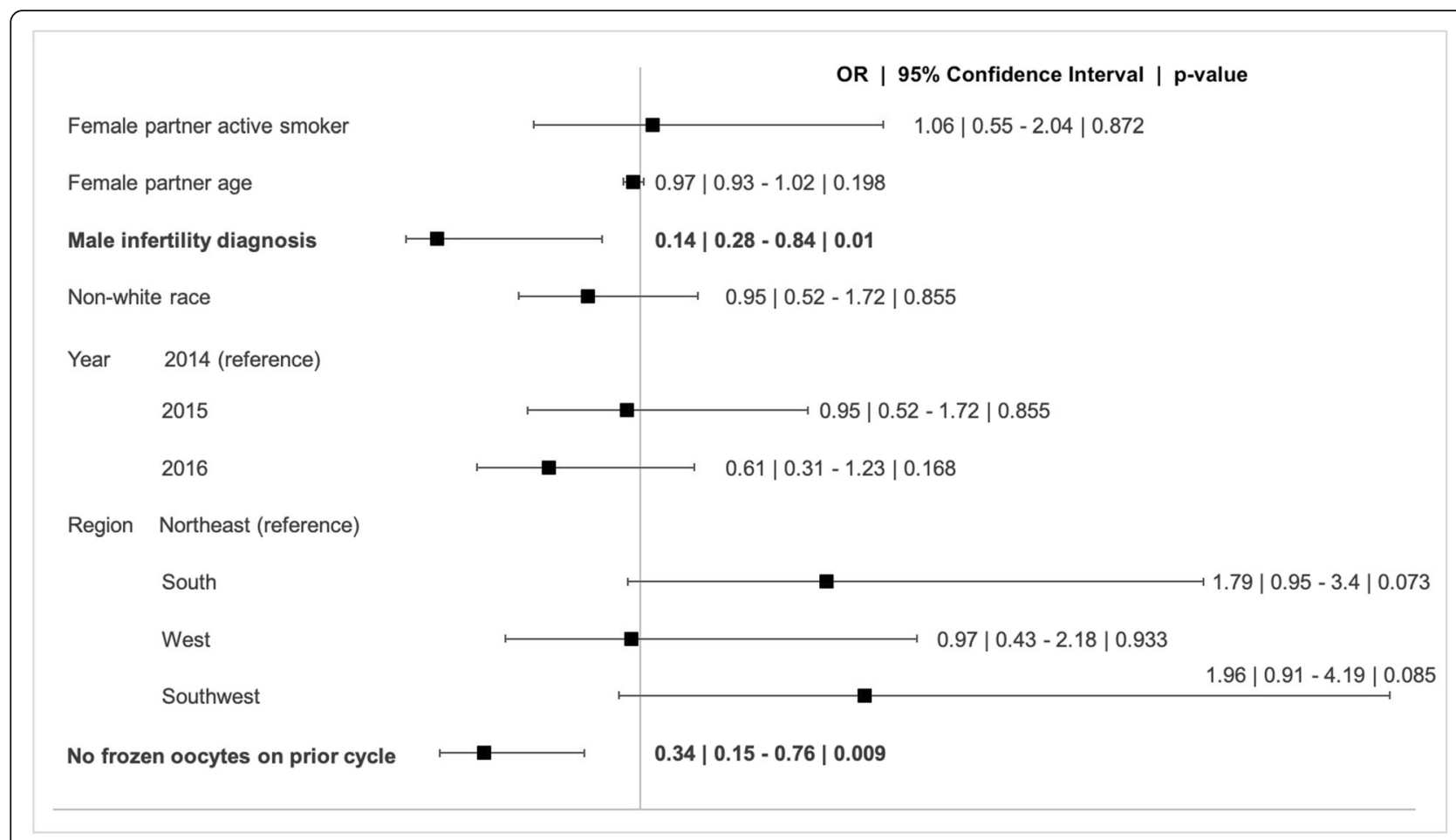

Fig. 1 Forest plot demonstrating multivariable analysis of predictors of undergoing subsequent cycles

Our results are surprising insofar as most of the instances of inability to obtain sperm for IVF relied on ejaculated sperm, indicating varied causes including sexual dysfunction or insufficient numbers of ejaculated sperm. Delayed orgasm or anorgasmia, however transient, may ultimately be at fault. Secondary orgasm dysfunction, resulting later in life, may be due to selective

Table 3 Multivariable analysis of factors predicting cryopreservation of eggs

\begin{tabular}{llll}
\hline & Odds Ratio & p-value & [95\% Conf. Interval] \\
\hline Female partner active smoker & 1.92 & 0.22 & $0.68-5.47$ \\
Female partner age & 1.06 & 0.074 & $0.99-1.14$ \\
Male infertility diagnosis & 1.11 & 0.809 & $0.48-2.59$ \\
Non-white race & 1.10 & 0.804 & $0.53-2.29$ \\
& & & \\
& Reporting Year & \\
2014 & reference & & \\
$\mathbf{2 0 1 5}$ & $\mathbf{3 . 0 8}$ & $\mathbf{0 . 0 1 3}$ & $\mathbf{1 . 2 7 - 7 . 4 9}$ \\
2016 & 1.69 & 0.284 & $0.65-4.41$ \\
& & & \\
South & Region & & \\
Northeast & reference & & \\
Midwest & $\mathbf{3 . 3 2}$ & $\mathbf{0 . 0 0 4}$ & $\mathbf{1 . 4 7 - 7 . 4 8}$ \\
West & $\mathbf{3 . 4 0}$ & $\mathbf{0 . 0 3 3}$ & $\mathbf{1 . 1 - 1 0 . 4 4}$ \\
\hline
\end{tabular}

serotonin reuptake inhibitors, hyperprolactinemia, chronic penile stimulation, or psychogenic/situational reasons [5]. This result underscores the importance of a sexual history intake during the couple's initial evaluation for infertility. Abnormal findings should prompt referral to a male reproductive medicine specialist [11]. Options for such men may include cryopreservation of ejaculated sperm ahead of time, planned electroejaculation in cases of known ejaculatory failure, penile vibratory stimulation, or even SSR. Electroejaculation has a high success rate among men with psychogenic anorgasmia, but requires sedation [12]. One study found the risk of transient azoospermia on the day of IVF is $52 \%$ among men with a prior semen analysis with a total count less than 100,000. Thus, such men with cryptozoospermia or severe oligozoospermia are at high risk for transient azoospermia and should be especially encouraged to cryopreserve sperm [7].

Sperm cryopreservation may help avoid instances of failed IVF cycles due to an inability to obtain sperm. Cost for elective sperm cryopreservation remain high and insurance coverage in men without azoospermia is poor. Unfortunately, there is limited insurance coverage for sperm cryopreservation and out-of-pocket costs can be significant at over $\$ 1000$ for processing, with further yearly fees for maintenance [15]. The fertilization and pregnancy rates are similar when comparing "fresh" versus cryopreserved/thawed testicular sperm obtained 
Table 4 Multivariable analysis of predictors of undergoing subsequent cycles

\begin{tabular}{|c|c|c|c|c|}
\hline \multirow[b]{2}{*}{ Female partner active smoker } & \multirow{2}{*}{$\begin{array}{l}\text { Odds Ratio } \\
1.06\end{array}$} & \multirow{2}{*}{$\begin{array}{l}p \text {-value } \\
0.87\end{array}$} & \multicolumn{2}{|c|}{ [95\% Conf. Interval] } \\
\hline & & & 0.55 & 2.04 \\
\hline Female partner age & 0.97 & 0.20 & 0.93 & 1.02 \\
\hline Male infertility diagnosis & 0.14 & 0.01 & 0.28 & 0.84 \\
\hline Non-white race & 0.78 & 0.30 & 0.48 & 1.25 \\
\hline \multicolumn{5}{|l|}{ Reporting Year } \\
\hline 2014 & reference & & & \\
\hline 2015 & 0.95 & 0.86 & 0.52 & 1.72 \\
\hline 2016 & 0.61 & 0.17 & 0.31 & 1.23 \\
\hline \multicolumn{5}{|l|}{ Region } \\
\hline Northeast & reference & & & \\
\hline South & 1.79 & 0.07 & 0.95 & 3.40 \\
\hline West & 0.97 & 0.93 & 0.43 & 2.18 \\
\hline Southwest & 1.96 & 0.09 & 0.91 & 4.19 \\
\hline No frozen oocytes on prior cycle & 0.34 & 0.01 & 0.15 & 0.76 \\
\hline
\end{tabular}

from men with NOA [9]. However, even prior sperm cryopreservation may not guarantee the presence of sperm for IVF as there are rare instances of post-thaw cellular loss among men with severe oligozoospermia or cryptozoospermia [6]. Yet, such costs of sperm cryopreservation pale in comparison to the costs of a failed IVF cycle due to the unavailability of sperm.

The costs and medical risks of IVF are a concern, making it of paramount importance to avoid such instances of canceled IVF cycles. While insurance mandates for IVF coverage are expanding, in the absence of such coverage, out-of-pocket costs for IVF can exceed $\$ 20,000$ [18]. The risks of ovulation induction include rare instances of ovarian hyperstimulation syndrome and surgical risk, which otherwise would be avoided if IVF were forgone due to a prior knowledge of an inability to obtain sperm [14]. Furthermore, one study found that only a minority of women would ultimately opt to use donor sperm after suffering a failed cycle of IVF due to an inability to surgically obtain sperm from her partner [10]. Indeed, this attitude was confirmed in our study, as only a minority of couples attempted a further cycle of IVF after the initial failure with even fewer subsequently utilizing donor sperm.

While this is a large national cohort, one limitation includes the retrospective nature of the data. There is limited granularity regarding the underlying etiology of male factor infertility (e.g., obstructive azoospermia due to vasectomy versus spermatogenic dysfunction), which precludes further the generalizability of the results. The database does not allow for linking to previous semen analyses prior to IVF. Furthermore, the database utilized only includes data from 2014 to 2016 and there were only 719 total cycles in which there was failure to obtain sperm. As data from subsequent years becomes available additional conclusions may be drawn with more representative cycles. A future area of potential study is comparing this data from the United States with data obtained within similar databases in other countries. Furthermore, there is a need for future multi-intuitional cohorts to examine this question with more detail about the male partners history.

\section{Conclusion}

This study shows that IVF cycles are only rarely canceled to an inability to obtain sperm. Ejaculated sperm was the most common expected source of sperm leading to cancelation. Most affected couples will not pursue further cycles of IVF after their initial failed attempt.

\section{Acknowledgements}

None

Capsule

Failure to obtain sperm during fresh IVF cycles is a rare occurrence, most often resulting due to inability to provide an ejaculated specimen. A minority of affected couples pursued further cycles of IVF.

\section{Authors' contributions}

AJB assisted with study design, performed statistical analyses and was a major contributor in writing the manuscript. VP assisted with study hypothesis and design and contributed to writing the manuscript. RAG assisted with study hypothesis and design and contributed to writing the manuscript. AL assisted with statistical design and performed statistical analyses. MK was the study originator, major contributor to study hypothesis and design and was a major contributor in writing the manuscript. All authors read and approved the final manuscript.

Funding

Not applicable

\section{Availability of data and materials}

The datasets during and/or analyzed during the current study available from the corresponding author on reasonable request. 


\section{Ethics approval and consent to participate}

Exemption was obtained from Institutional Review Board at Brigham and Women's Hospital for this study.

\section{Consent for publication}

Not applicable

\section{Competing interests}

The authors declare that they have no competing interests

\section{Author details}

'Division of Urology, Brigham and Women's Hospital and Harvard Medical School, 45 Francis St ASB-II, Boston, MA 02115, USA. ²Department of Obstetrics and Gynecology, Center for Infertility and Reproductive Surgery, Brigham and Women's Hospital and Harvard Medical School, 75 Francis Street, Boston, MA 02115, USA.

Received: 27 February 2020 Accepted: 13 July 2020 Published online: 11 August 2020

\section{References}

1. Anger JT, Gilbert BR, Goldstein M. Cryopreservation of sperm: indications, methods and results. J Urol. 2003;170(4):1079-84. https://doi.org/10.1097/01. JU.0000084820.98430.B8.

2. Bernie AM, Mata DA, Ramasamy R, Schlegel PN. Comparison of microdissection testicular sperm extraction, conventional testicular sperm extraction, and testicular sperm aspiration for nonobstructive azoospermia: a systematic review and meta-analysis. Fertility Sterility. 2015;104(5):10991103.e3. https://doi.org/10.1016/J.FERTNSTERT.2015.07.1136.

3. Esteves S, Prudencio C, Seol B, Verza S, Knoedler C, Agarwal A. Comparison of sperm retrieval and reproductive outcome in azoospermic men with testicular failure and obstructive azoospermia treated for infertility. Asian J Androl. 2014;16(4):602. https://doi.org/10.4103/1008-682x.126015.

4. Hull MG, Glazener CM, Kelly NJ, Conway DI, Foster PA, Hinton RA, et al. Population study of causes, treatment, and outcome of infertility. Br Med $J$ (Clin Res Ed). 1985;291(6510):1693-7. https://doi.org/10.1136/bmj.291.6510. 1693.

5. Jenkins LC, Mulhall JP. Delayed orgasm and anorgasmia. Fertil Steril. 2015; 104(5):1082-8. https://doi.org/10.1016/J.FERTNSTERT.2015.09.029.

6. Kathrins M, Abhyankar N, Shoshany O, Liebermann J, Uhler M, Prins G, Niederberger $C$. Post-thaw recovery of rare or very low concentrations of cryopreserved human sperm. Fertil Steril. 2017;107(6):1300-4. https://doi. org/10.1016/j.fertnstert.2017.04.016.

7. Montagut M, Gatimel N, Bourdet-Loubère S, Daudin M, Bujan L, Mieusset R, et al. Sperm freezing to address the risk of azoospermia on the day of ICSI. Hum Reprod. 2015;30(11):2486-92. https://doi.org/10.1093/humrep/dev234.

8. Nicopoullos JDM, Gilling-Smith C, Almeida PA, Norman-Taylor J, Grace I, Ramsay JWA. Use of surgical sperm retrieval in azoospermic men: a metaanalysis. Fertil Steril. 2004;82(3):691-701. https://doi.org/10.1016/j.fertnstert. 2004.02.116.

9. Ohlander S, Hotaling J, Kirshenbaum E, Niederberger C, Eisenberg ML. Impact of fresh versus cryopreserved testicular sperm upon intracytoplasmic sperm injection pregnancy outcomes in men with azoospermia due to spermatogenic dysfunction: a meta-analysis. Fertil Steril. 2014;101(2):344-9. https://doi.org/10.1016/j.fertnstert.2013.10.012

10. Palermo GD, Neri QV, Schlegel PN, Rosenwaks Z. Intracytoplasmic sperm injection (ICSI) in extreme cases of male infertility. PLoS One. 2014;9(12): e113671. https://doi.org/10.1371/journal.pone.0113671.

11. Penzias A, Bendikson K, Butts S, Coutifaris C, Falcone T, Fossum G, et al. Diagnostic evaluation of sexual dysfunction in the male partner in the setting of infertility: a committee opinion. Fertil Steril. 2018;110(5):833-7. https://doi.org/10.1016/j.fertnstert.2018.07.010.

12. Schatte EC, Orejuela FJ, Lipshultz LI, Kim ED, Lamb DJ. Treatment of infertility due to anejaculation in the male with electroejaculation and intracytoplasmic sperm injection. J Urol. 2000;163(6):1717-20.

13. SCHOOR RA, ELHANBLY S, NIEDERBERGER CS, ROSS LS. The role of testicular biopsy in the modern management of male infertility. J Urol. 2002;167(1): 197-200. https://doi.org/10.1016/S0022-5347(05)65411-0.

14. Serour Gl, Aboulghar M, Mansour R, Sattar MA, Amin Y, Aboulghar $H$. Complications of medically assisted conception in 3,500 cycles. Fertil Steril. 1998;70(4):638-42. https://doi.org/10.1016/S0015-0282(98)00250-7.
15. Sonnenburg DW, Brames MJ, Case-Eads S, Einhorn LH. Utilization of sperm banking and barriers to its use in testicular cancer patients. Support Care Cancer. 2015;23(9):2763-8. https://doi.org/10.1007/s00520-015-2641-9.

16. Thonneau P, Marchand S, Tallec A, Ferial M-L, Ducot B, Lansac J, et al. Incidence and main causes of infertility in a resident population (1 850 000) of three French regions (1988-1989)*. Hum Reprod. 1991;6(6):811-6. https:// doi.org/10.1093/oxfordjournals.humrep.a137433.

17. Weedin J, Bennett R, Fenig D, Lamb D, Lipshultz L. Early versus late maturation arrest: reproductive outcomes of testicular failure. J Urol. 2011; 186(2):621-6. https://doi.org/10.1038/nature11130.Reduced.

18. Wu AK, Odisho AY, Washington SL, Katz PP, Smith JF. Out-of-pocket fertility patient expense: data from a multicenter prospective infertility cohort. J Urol. 2014;191(2):427-32. https://doi.org/10.1016/j.juro.2013.08.083.

\section{Publisher's Note}

Springer Nature remains neutral with regard to jurisdictional claims in published maps and institutional affiliations.

\section{Ready to submit your research? Choose BMC and benefit from:}

- fast, convenient online submission

- thorough peer review by experienced researchers in your field

- rapid publication on acceptance

- support for research data, including large and complex data types

- gold Open Access which fosters wider collaboration and increased citations

- maximum visibility for your research: over $100 \mathrm{M}$ website views per year

At BMC, research is always in progress.

Learn more biomedcentral.com/submissions 